\title{
In Drug Delivery, Shape Does Matter
}

\section{Samir Mitragotri ${ }^{1,2}$}

Published online December 31, 2008

"Microfabricated Particles for Engineered Drug Therapies: Elucidation into the Mechanisms of Cellular Internalization of PRINT Particles" by Stephanie E. A. Gratton, Mary E. Napier, Patricia A. Ropp, Shaomin Tian, and Joseph M. DeSimone (DOI: 10.1007/s11095-008-9654-8) should have been included in the Theme Section on Micro/Nanocarriers (Vol. 26, No. 1) introduced by this Editorial, but was inadvertently published in Vol. 25, No. 12, pp. 2845-2852.

\footnotetext{
${ }^{1}$ Department of Chemical Engineering, University of California, Santa Barbara, California 93106, USA.

${ }^{2}$ To whom correspondence should be addressed. (e-mail: samir@engineering.ucsb.edu)

The online version of the original article can be found at: http://dx.doi.org/10.1007/s11095-008-9740-y.
} 